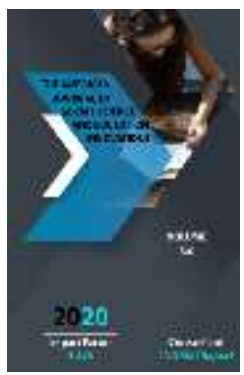

\title{
The Structure Of Information Competence Of High School Students
}

\author{
Abror Amrullayevich Karshiyev \\ Lecturer, Department Of Methodology And Its Teaching Of Informatics, Faculty Of \\ Mathematics And Informatics, Jizzakh State Pedagogical Institute, Jizzakh City, Uzbekistan
}

Journal Website:

http://usajournalshub.c

om/index,php/tajssei

Copyright: Original

content from this work

may be used under the

terms of the creative

commons attributes

4.0 licence.

\section{ABSTRACT}

The article is devoted to determining the structure of information competence of high school students. The development and application of modern information and communication technologies in all spheres of science, technology, education and industry at the present stage of integration development has influenced changes in the education system. The process of informatization of education is largely determined by the level of competence of students in the field of information and communication technologies. In this regard, teaching students who are able to use their knowledge in production with the use of new information technologies is a top priority for secondary schools. Comparing different approaches to this phenomenon, the authors try to find common elements in different classifications in order to propose a structure of information competence of high school students.

\section{KEYWORDS}

Competence, information, communication, information technology, information literacy, information competence, education, general education schools, high school students.

\section{INTRODUCTION}

The development and application of modern information and communication technologies in all spheres of science, technology, education and industry at the present stage of integration development has influenced changes in the education system. The process of informatization of education is largely determined by the level of competence of students in the field of information and communication technologies. In this regard, 
training students who are able to use their knowledge in production with the use of new information technologies is a priority task for a secondary school in the Republic of Uzbekistan. New demands in the education system make it necessary to increase the level of professional competence of teachers and the competence of secondary school students, who require knowledge, skills and abilities in the field of information and communication technologies.

The concepts of "competence" and "competence" were first introduced into the pedagogical lexicon in 1957, and their distinction is associated with the broadest criticism of the education system in the United States. At this stage in the development of pedagogical science, there was no precise definition of them, however, both "competence" and "competence" were considered as the main units of updating the content of education.

S.I. Ozhegov in the "Explanatory Dictionary of the Russian Language" interprets the concept of "competence" as "a range of issues in which someone is well aware", and the concept of "competence" - as "awareness, authority in some area" [1].

According to I.A. In winter, competence is some internal potential, latent psychological new formations (knowledge, ideas, action programs, value systems and attitudes), while competence is knowledge-based, intellectually and personally determined experience of a person's social and professional life, as if the use of a hidden, potential reserve [2].

The ambiguous interpretation of these concepts is given by A.V. Khutorskoy, defining "competence" in the general education system as a set of interrelated personality traits, reflecting the given requirements for the educational training of graduates, and "competence" as a person's possession of the appropriate competence [3].

Asserting that "competence is information awareness, deep knowledge about a specific subject, on the one hand, and a range of any powers, rights, on the other hand," while "competence is a specific education, a characteristic of a person, indicating his ability and the willingness to perform any functions within a certain competence "strict delineation of these concepts is carried out in his work by G.S. Vyalikov, [4].

The analysis of the above interpretations allowed us to concretize the concepts of "competence" and "competence" as follows. Competence means mastering a certain subject area, the ability to think in its categories, it is a complex (aggregate) of knowledge, skills and abilities formed in the learning process. In turn, competence is a specific personal formation that determines the subject's ability to perform any activity based on the formed competence (or a set of competencies).

\section{MAIN PART}

At present, one of the most urgent tasks of the school education system is the formation of a student's information competence, since competence integrates knowledge, skills and learned ways of activity in relation to specific conditions in a new situation, which requires a creative approach. The information society is becoming the appropriate environment. At the same time, the formation of information competence as a mandatory component of the professional competence of a future specialist 
is becoming an urgent problem, the solution of which is of great importance for each individual person and for society as a whole. It is information competence that characterizes deep awareness in the subject area of knowledge, the personal experience of the subject, aimed at promising work, at the formation of a modern scientific worldview; open to dynamic enrichment and selfimprovement through receiving, evaluating and using information; able to create new information; able to achieve significant results and high quality in professional activities.

To come to an understanding of the essence of the formation process of this type of competence, it is necessary, in our opinion, to distinguish between the concepts of "literacy" and "competence", and on this basis to characterize the categories derived from them: "information literacy" and "information competence".

\section{Comparing traditional dictionary} interpretations of the concepts of "literacy" and "competence", one can find their similarity and closeness. For example, S.I. Ozhegova, the word "competent" is understood as a person: “1) knowledgeable, knowledgeable, authoritative in some area; 2) possessing competence "[1], while a" literate person "is interpreted as:" 1) able to read and write, and also able to write grammatically correctly, without mistakes; 2) possessing the necessary knowledge, information in any area "[1].

Thus, literacy is the basics of culture, from which its development begins, as a rule, taking into account age, individual personality traits. Literacy is the foundation on which further human development can be built. By opening access to the book, literacy makes it possible to use the treasury of thought and knowledge created by all of humanity. The specific content of the concept of literacy is historically changeable, tends to expand with the growth of social requirements for the development of an individual: from elementary skills to read, write, and count - to possession of a complex of various socially necessary knowledge and skills that allow a person to consciously participate in social processes.

Literacy implies a person's ability to perceive and express information in text form. This means the mastery of knowledge that manifests itself in the outlook, erudition, awareness, both from the point of view of scientific knowledge, and from the point of view of everyday experience derived from traditions, customs, direct communication of a person with other people, and also involves mastering the system of signs and their values. As a term, literacy has a thousand-year history and the addition of the definition of "information" to it only emphasizes the secondary purpose of modern information and communication technologies in mastering the cultural heritage of mankind. The main difference between literacy and competence is that a competent person has knowledge, and a competent person can (is ready) to use this knowledge in solving practical problems. Distinguishing literacy and competence in behavioral characteristics, it can be argued that a literate person knows, understands, for example, how to behave in a certain situation, and a competent person can actually and effectively use knowledge in solving certain problems.

With all the similarity of the definitions of the analyzed concepts, one cannot but agree with N.I. Gendina is that in the everyday, widespread understanding, in the very word 
"literacy" there is a shade of elementarity, primitiveness, a reflection of the simplest, initial level of education [5]. At the same time, the term "competence" seems to us more specific and targeted in relation to the experience, knowledge and skills of a person, their application in activities.

Among the key concepts that are important for determining the essence and content of students' information competence are the concept of "information".

In the context of education I.V. Robert proposes to interpret the concept of "information" as information about factual data and a body of knowledge about the dependencies between them, considering the named phenomenon also as a means by which "society can be aware of itself and function as a whole" [6]. The saturation of society with information, constantly changing and updating, leads to the conclusion that in modern conditions it is no longer enough to build an education strategy only on the assimilation of ready-made knowledge. It is important to equip students with techniques and methods of searching, analyzing, processing, storing, using and producing information, transmitting / broadcasting it. The transfer of information in the course of communication is the essence of one of the specific forms of interaction between members of human society in general and a teacher and a student, in particular, namely communication.

Communication is the exchange of information between individuals through a common system of symbols, in other words, it is the process of encoding and transmitting information from the source and reception by the recipient of a message.
Communication and information are the driving forces of progress, contributing to an increase in the level and quality of life, which are not limited by any subject, place or time and play a vital role in ensuring a wide variety of spheres of human life, including education.

As shown earlier, literacy is the basis for the formation of competence. Developing this idea, we can assume that the first stage in the formation of information competence of high school students is the formation of information literacy. Two components are clearly visible in its structure: information and communication literacy.

For the first time the concept of "information literacy" was introduced in 1977 in the United States and was used in the national program for the reform of higher education. According to American educational standards, an information literate student is able to find the right information, determine its accuracy, figure out where the facts are and where the opinions are, and discard the inappropriate information.

A.V. Goryachev significantly expands the scope of "information literacy" and proposes to include the following skills in this concept, bringing it closer to "information competence": to identify possible sources of information, a strategy for its search and receipt; analyze the information received using various types of schemes, tables, etc. to record the results; evaluate information from the point of view of its reliability, accuracy, sufficiency for solving the problem (task); feel the need for additional information, receive it, if possible; build up your own knowledge bank at the expense of personally meaningful information necessary for your activities in various fields; use modern technologies when 
working with information; work with information individually and in a group [7].

Based on this interpretation of the content of this concept, it can be assumed that the development of information literacy by a person forms the basis for a continuous process of education and self-education. This characteristic is relevant to any discipline, any educational environment, all levels of education and means the ability to determine your information needs, possible sources of information, search for and obtain information, its assessment, selection and effective use.

Considering that the acquisition of solid knowledge is impossible without their constant updating, it can be assumed that in parallel with the formation of information literacy in the preparation of students, the formation of its communication literacy should also be carried out. It should be noted that this concept is rarely singled out in the works of researchers, where communication culture and communication technologies are mostly considered. However, it should be recognized that a person who owns a communication culture, uses communication technologies, cannot avoid passing the first stage in their development, namely, the formation of communication literacy.

During the formation of the information society, the information space becomes one of the important environments for human communication. It is interpreted as a set of banks and databases, technologies for their maintenance and use, information telecommunication systems that provide information interaction between organizations and citizens, as well as the satisfaction of their information needs, that is, a means by which society can become aware of itself and function as a whole. Therefore, communication literacy should be understood as the ability to navigate the information space and use information and communication technologies to exchange information while maintaining social and professional contacts.

There is no consensus among researchers in the definition of information literacy. If V.F. Burmakina defines it as "the use of digital technologies, communication tools, networks to gain access to information, manage it, integrate it, assess the creation of a transmission for functioning in modern society" [8], then according to Z.N. Novikova, information literacy is the user's ability to use a computer and information technology as a tool in their immediate activities [9].

Linda H. Scatton points out the following content of information and communication literacy: it is "the use of digital technologies, means of communication and communication and / or networks to gain access, control, integrate, evaluate and create information so that a person can function in a society based on knowledge " [ten].

Thus, if literacy presupposes what characteristics a person should have in order to be called literate in a certain area, then the list of information literacy content should include the following knowledge, skills and abilities: knowledge of basic concepts and terms (information, multimedia communication, software provision, expert training systems, artificial intelligence systems, etc.), information models, basic means and capabilities of information technologies, communication tools, etc.; the ability to determine possible sources and type of information, a strategy for its search, to access 
information; the ability to store, analyze, evaluate, interpret, create, present information; skills in processing text documents, graphic objects, tabular data based on information and communication technologies, skills in the operating system, in local and global networks, etc.

Therefore, information literacy is the possession of a set of knowledge, skills and abilities that provide the ability to use digital technologies and communication tools in order to define information, gain access, manage, integrate, evaluate, create and communicate information. Since professional excellence should be based on the unity of abilities, qualities, experience, knowledge and skills corresponding to the modern level of development of science, technology and their product - information and communication technologies, it can be argued that information literacy is today an important part of a specialist's knowledge and skills. components of his professionalism. Possession of such a complex of knowledge, skills and abilities will allow solving one's professional tasks at a qualitatively higher level: freely, appropriately and adequately use the means of information and communication technologies in professional activities; navigate the modern information space; provide oneself with the necessary material, including using a distributed resource; present this material in a modern form, etc. However, in the approaches of modern scientists to the definition of this phenomenon, there is no unity of opinion.

For our study, the opinion of E.K. Henner [11], who notes that information competence includes individual activity abilities and qualities, which determine the following capabilities and skills: independently seek, collect, analyze, present, transmit information; design and simulate objects and processes (including your own individual activities); to model and design the work of the team; make decisions, creatively and effectively solve problems in the process of productive activity; navigate the organizational environment based on modern information and communication technologies; responsibly implement their plans, using modern information and communication technologies; use modern information and communication technologies in their professional activities.

\section{RESULTS AND DISCUSSIONS}

The analysis of the above works showed that information competence consists of a set of competencies - basic human qualities, which are the reason for the effective and best performance of work, determined on the basis of certain criteria. We distinguish the following grounds for determining the content and structure of competencies: motives - what a person thinks or wants constantly and what causes action; for example, the desire to receive important information for professional activities; goal-setting - the ability to set a goal and organize its achievement, the ability to substantiate one's goal; planning - the ability to organize planning, analysis, reflection, selfassessment of their educational and cognitive activities; psychophysiological characteristics (properties) - physical characteristics and corresponding reactions to a pedagogical situation or professionally important information; for example, self-control; attitudes and values - personal characteristics, ideas of a high school student about himself; for example, the belief that he can master information technologies and use them effectively in educational work; the knowledge 
that the student has about what information is, what are its types, forms, development tools, methods and techniques for working with it; skills - the ability to perform a specific task; for example, the search for information, its systematization, etc., the ability to organize self-study through distance educational technologies; skills - skills brought to automatism; for example, skills in the use of telecommunication technologies in a specific subject, taking into account its specifics.

Based on the above, we consider the information competence of a high school student as an emotional-value attitude to information activities, readiness to creatively perform various types of it on the basis of mastering systemic knowledge, abilities and skills, experience in information activities in order to solve developing educational problems and prepare for continuing professional education ...

In our opinion, information competence is a phenomenon of a higher order, which is approximately the same correlated with information and communication literacy as stable professional skills in an intellectually capacious profession correlate with elementary literacy.

Therefore, the information competence of high school students in secondary school should be understood as integrative personal education, characterized by: a set of systemic scientific knowledge, abilities and skills formed in a specially organized process of teaching computer science; the ability to navigate in the educational environment based on modern means of information and communication technologies and the willingness to creatively use them in their professional activities; a deliberate desire for continuous self- improvement in the field of information and communication technologies.

Information competence is one of the innovative components that allows you to master new knowledge at a qualitatively new level; adjust and form effective strategies for the development of abilities and skills in certain types of activities; restore lost knowledge, skills and abilities; control, develop and evaluate the current level of knowledge and skills; to develop skills and abilities for solving practical problems in the chosen subject area; analyze and make decisions in non-standard problem situations. The need to implement these skills is due to the need for modern school education in new forms and methods of teaching, expanding the information field, information technology of the educational process.

Having analyzed and generalized approaches to the definition of competence, we believe that competence has a personal component, which is associated with the socio-cultural development of the individual and society as a whole. Clarification of the structure and content of the information competence development technology is one of the promising directions for improving the system of pedagogical space.

Based on the proposed interpretation of the content of information competence, in its structure, we have identified the following components in relation to high school students:

1. The cognitive component - knowledge about information - includes knowledge of various sources of information, forms and methods of working with information, 
knowledge of search information systems, and the ability to present information.

2. The activity component - includes the collection and processing of educational information, the development of creative projects, knowledge of methods of analysis, synthesis and generalization of information, the ability to technologize work with information, to choose the optimal solution, which is the active use of information and communication technologies in professional activities as a means knowledge and development, selfimprovement and creativity. In this component, the requirements for knowledge and skills, tested in action, are highlighted, which implies the practical preparation of a teacher for professional activity in the context of the informatization of society.

3. The reflective component - creative application of information - includes the ability to conduct self-control, satisfaction with information activities, reflection of the results of the process of working with information, interaction in the transfer of information, communication and joint activities, the ability to organize, correction of professional information, awareness and critical analysis of information activities, creation of your own creative projects. The reflexive-communicative component contributes to the development of the student's creativity, self-development, mastering the methods of communication with partners in educational activities, the formation of skills to work autonomously and in a team, the implementation of a system of connections: interpersonal interaction of subjects, connections with the academic subject and the computer environment.

4. The value-motivational component attitude and request for information includes the high school student's awareness of the value of working with information, motivation to search for meaningful information, understanding the value of using information technology, striving for self-education, goal setting when working with information, the need to work with information, the formation of the student's subject position, orientation in the information environment, readiness to use information resources as a source of knowledge. The value-motivational component is associated with the creation of conditions conducive to overcoming internal barriers, restructuring the consciousness of a senior pupil, his psychological readiness to work in an information environment. This is achieved through the formation of attitudes, interest, strong motivation, increased student activity in the use of various types of information in their professional activities. The student's need to engage in self-education in the process of informational activity should bring satisfaction, not cause great efforts to organize classes in active informational activity. The value-motivational component contributes to the entry of high school students into the information and educational space, awareness of the value of information; characterizes the degree of the student's motivational impulses; highlights the value-semantic aspects of the information activity of the senior pupil. 


\section{CONCLUSION}

The named components, which are part of integrative personal education, are in close interconnection, interdependence, as well as in mutual influence and interpenetration, while the formation of each of them is associated with the formation of its characteristics and properties as part of an integral system.

The formed information competence will allow students to use the achievements of modern science and practice in the field of information and communication technologies in their professional activities, to maximize their opportunities to increase its effectiveness.

\section{REFERENCES}

1. Ozhegov S.I. Dictionary of the Russian language: 70,000 words / ed. N.Yu. Shvedova. - 23rd ed., Rev. - M .: Rus. yaz., 1991 .- 917 p.

2. Zimnyaya I.A. Key competencies - a new paradigm of the result of education // Higher education today. - 2003. - No. 5. - P. 45.

3. Khutorskoy A.V. Key competencies and educational standards // Department of Philosophy of Education and Theoretical Pedagogy of the Russian Academy of Education, Center "Eidos", 23.04.2002. URL: www.eidos.ru/news/compet.htm.

4. Vyalikova G.S. Pedagogical stimulation of professional teacher's competence in the conditions of correspondence education: author. dis. ... D. Ped. sciences. - Ryazan, 2006 .- 40 p.

5. Gendina N.I. Information literacy or information culture: alternative or unity (results of Russian research) // School Library. - 2005. - No. 3. - P. 18-19.

6. Robert I.V. Directions of scientific research in the field of education reform in connection with the use of information and communication technologies // Informatization of lifelong education: materials of the VII International Exhibition - Fair. - M., - 1997. - S. 21-27.

7. Goryachev A.V. Formation of information literacy in the educational system "School 2100". [Electronic resource]. URL: www.school2100.ru.

8. Burmakina V.F. Measuring the levels of information and communication competence of schoolchildren. Approaches and Techniques. URL: www.metodisty.narod.ru.

9. Novikova A.A. Media education in the United States: problems and trends // Pedagogy. - 2000. - No. 3. - P. 68-75.

10. Scatton Linda H. Approach to ICT Literacy: Report of the International Commission. URL: http://www.ict.edu.ru/vconf.

11. Henner, E.K. Formation of ICT competence of students and teachers in the system of continuous education / E.K. Henner. Moscow: BINOM. Knowledge Laboratory, 
2015 -- 191 p. - ISBN 978-5-9963-2617-4. -

Text: direct.

12. Farfieva K. A. Social Media as a factor in formation of scientific thinking in youth. European Journal of Research and Reflection in Educational Sciences. Vol. 8 No. 10, 2020. - Pp. 52-56. 